\title{
Application of cyanoacrylate in difficult-to-arrest acute non-variceal gastrointestinal bleeding
}

\author{
Krzysztof Kurek, Andrzej Baniukiewicz, Agnieszka Świdnicka-Siergiejko, Andrzej Dąbrowski
}

Department of Gastroenterology and Internal Medicine, Medical University of Bialystok, Poland

Videosurgery Miniinv 2014; 9 (3): 489-493

DOI: $10.5114 /$ wiitm.2014.44169

\begin{abstract}
Gastrointestinal bleeding is a common medical emergency. Although endoscopic treatment is effective in controlling non-variceal upper gastrointestinal bleeding, in cases of persistent bleeding radiological or surgical interventions are required. Application of cyanoacrylate for treatment of difficult-to-arrest non-variceal upper gastrointestinal bleeding is poorly investigated. We describe patients in whom cyanoacrylate for acute non-variceal gastrointestinal bleeding was used to stop the bleeding after failure of conventional endoscopic treatment. Five patients were treated with cyanoacrylate application (injection and/or spraying) for persistent bleeding (duodenal ulcer in 3, gastric ulcer in 1 and gastric Dieulafoy's lesion in 1) despite conventional endoscopic therapies. Hemostasis was achieved in all patients (100\%). One patient (20\%) developed recurrent bleeding 4 days after initial treatment. No complications or adverse events attributed to the cyanoacrylate application during the follow-up period of 57 days were observed. Application of cyanoacrylate is a safe and effective method to achieve immediate hemostasis when conventional endoscopic treatment is unsuccessful. This technique is easy to perform and should be considered in cases of patients with difficult-to-arrest acute non-variceal upper gastrointestinal bleeding.
\end{abstract}

Key words: cyanoacrylate, endoscopic therapy, endoscopic therapy, tissue adhesives.

\section{Introduction}

Acute non-variceal upper gastrointestinal bleeding (NUGIB) is a common medical emergency worldwide. This condition is characterized by fresh blood or coffee ground emesis and melena [1]. Endoscopic treatment of acute non-variceal gastrointestinal bleeding involves injection, thermal, and mechanical methods. These are highly effective management techniques in controlling gastrointestinal bleeding, and therefore the frequency of emergency surgery is continuously decreasing (from 8\% to 2\% between 1993 and 2006 in the U.K. and from 21\% to $9 \%$ between 1993 and 2006 in the U.S.) [2, 3]. However, in $5-15 \%$ of patients, an endoscopy does not provide successful arrestment of bleeding and in these situations radiological or sur- gical interventions are still required $[4,5]$. Nevertheless, it should be emphasized that these methods are associated with higher morbidity and mortality compared to endoscopic therapy $[6,7]$.

Cyanoacrylate (n-butyl-2-cyanoacrylate; Histoacryl; Braun, Germany) is a liquid tissue adhesive, consisting of monomers which rapidly polymerize (creating long and strong chains) in an exothermic reaction after contact with hydroxide ions [8]. Application of cyanoacrylate in the endoscopic treatment of gastric and esophageal varices has been well established since Soehendra et al. reported this method for the first time in 1986 [9]. Although cyanoacrylate is commonly used in many European and Asian medical centers, the U.S. Food and Drug Administration (FDA) limited its widespread application in the U.S. because

\section{Address for correspondence}

Krzysztof Kurek MD, PhD, Department of Gastroenterology and Internal Medicine, Medical University of Bialystok, 24 A M. Sklodowskiej-

Curie St, 15-276 Bialystok, Poland, phone: +48 660484 780, e-mail: krzysztof.kurek@umb.edu.pl 


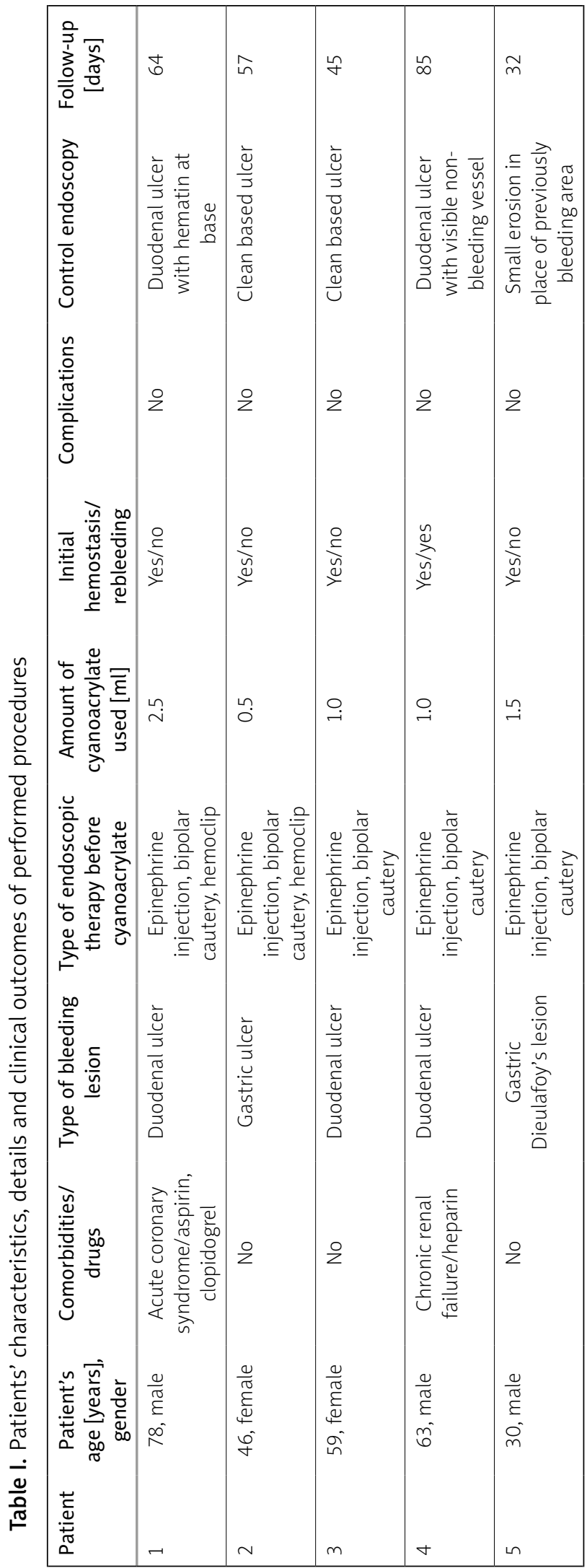

of infrequent but severe thromboembolic complications [10]. Nonetheless, the FDA approves the use of cyanoacrylate for wound closure [11].

In this study we report 5 cases of patients with difficult-to-arrest acute NUGIB successfully treated with cyanoacrylate.

\section{Case reports}

We describe in detail 5 patients, who were hospitalized in the Department of Gastroenterology and Internal Medicine, the Medical University of Bialystok, between September 2012 and August 2013, in whom cyanoacrylate for acute non-variceal gastrointestinal bleeding was used to stop the bleeding. All esophagogastroduodenoscopies (EGD) were performed by the same experienced endoscopist. The decision to apply cyanoacrylate was made when other widely accepted endoscopic hemostatic treatments (epinephrine injections, bipolar electrocoagulation, hemostatic clips) were unsuccessful. Cyanoacrylate $(0.5-2.5 \mathrm{ml})$ was injected into the bleeding vessel. In 1 case cyanoacrylate was also sprayed over the bleeding lesion using a 23G injection needle. Immediately after injection or spraying, cyanoacrylate residues were flushed out from the needle with $3 \mathrm{ml}$ of saline solution. Afterwards, the endoscope was inserted again in order to verify the effectiveness of the performed procedure.

Five patients ( 3 males and 2 females, median age: 55 years, range: $30-78$ years) with persistent acute NUGIB (after failure of conventional endoscopic therapy modes) were treated with a cyanoacrylate injection and/or spraying. Application of cyanoacrylate provided immediate haemostasis in all 5 cases (100\%). Re-bleeding only occurred in 1 case (20\%) 4 days after the initial treatment. This patient underwent upper gastrointestinal tract endoscopic reexamination and the bleeding was successfully treated with conventional endoscopic methods. None of the patients experienced complications or adverse events related to the cyanoacrylate injection or spraying during the follow-up period of 57 days (range: 32-85 days). The patients' characteristics, procedural details, and clinical outcomes are described below and summarized in Table I.

\section{Patient 1}

A 78-year-old man, admitted with acute coronary syndrome, was treated with two antiplatelet 
agents (aspirin and clopidogrel). On the $4^{\text {th }}$ day of hospitalization he reported hematemesis and melena. Upper gastrointestinal endoscopy revealed a $1.5 \mathrm{~cm}$ ulcer on the anterior wall of the duodenal bulb with a visible $2 \mathrm{~mm}$ non-bleeding vessel (Forrest IIA). While the vessel was being injected with an epinephrine solution (1: 10 000), arterial spurting occurred (Forrest IA). Attempts to achieve hemostasis with an epinephrine injection, hemostatic clips and application of a bipolar cautery failed and the bleeding was finally stopped after $1.0 \mathrm{ml}$ ( 2 injections of $0.5 \mathrm{ml}$ ) of cyanoacrylate was injected into the vessel, followed by spraying $1.5 \mathrm{ml}$ of cyanoacrylate over the bleeding area (Photo 1 ). The control EGD, performed 5 days after the initial
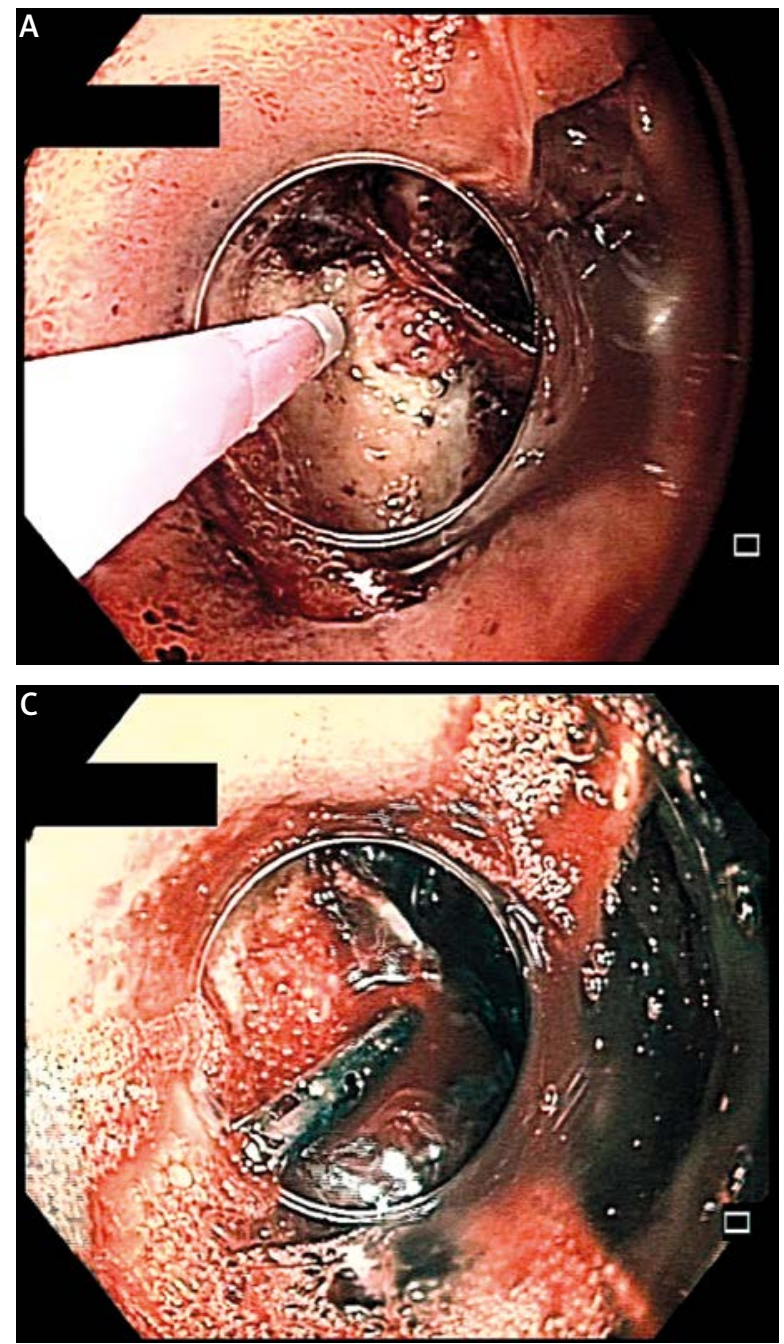

procedure, showed the ulcer with hematin at the base (Forrest IIC) localized on the anterior wall of the duodenal bulb.

\section{Patient 2}

A 46-year-old woman, without serious comorbidities, presented with melena. Upper gastrointestinal endoscopy revealed a $1.0 \mathrm{~cm}$ ulcer, situated in the region of a gastric angular incisure with oozing bleeding (Forrest IB). Despite an epinephrine solution (1 : 10 000) injection, bipolar cautery coagulation and the application of hemostatic clips, bleeding continued. Subsequently, $0.5 \mathrm{ml}$ of cyanoacrylate was injected into the bleeding lesion and hemostasis was achieved. The control EGD, implemented
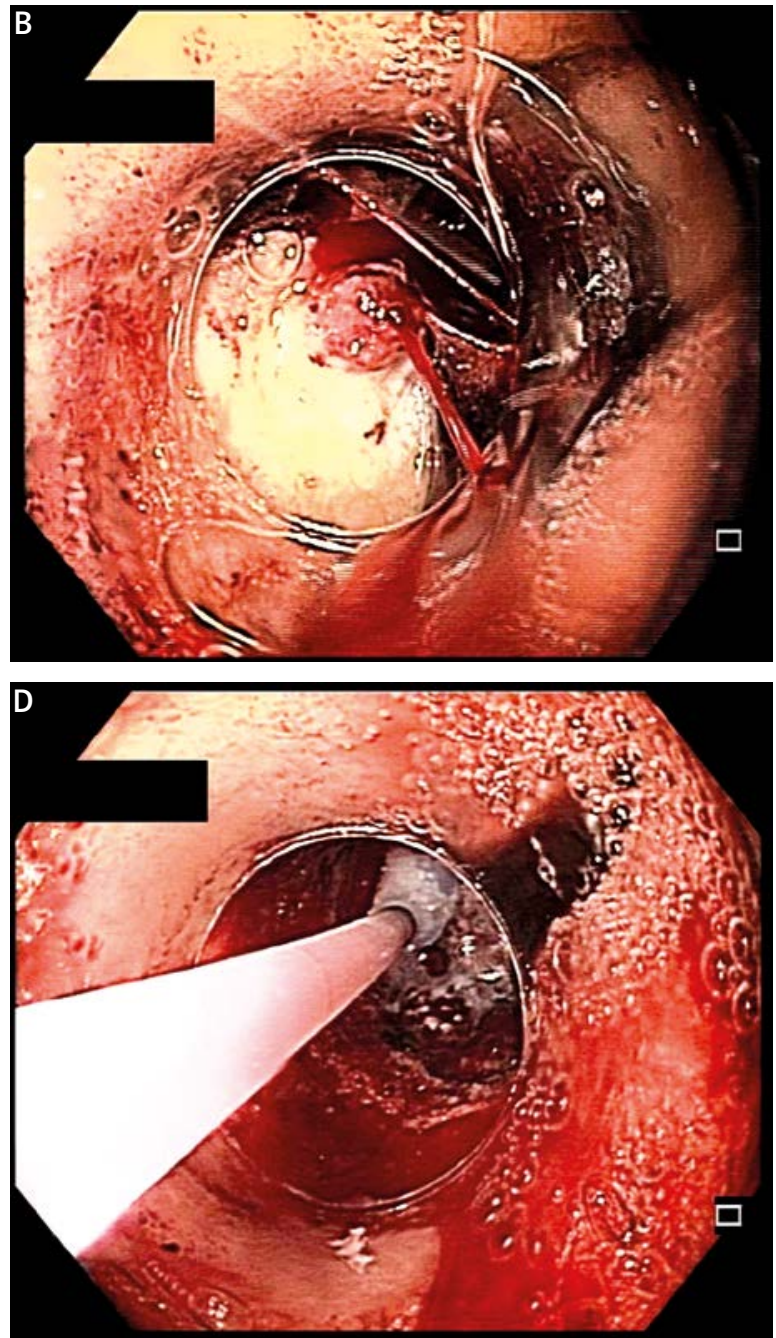

Photo 1. Patient 1. A - Non-bleeding vessel in duodenal ulcer base, epinephrine solution injection is being performed. B - Spurting arterial bleeding after epinephrine injection. $\mathbf{C}$ - Active bleeding despite hemostatic clip placement. D - Hemostasis achieved after injection and spraying of cyanoacrylate 
5 days later, revealed a healing ulcer in the place of the previously bleeding area (Forrest III).

\section{Patient 3}

A 59-year-old woman, without serious comorbidities, was admitted with melena and coffee ground emesis. The EGD was performed immediately after admission and it demonstrated a $2.0 \mathrm{~cm}$ posterior wall duodenal bulb ulcer with arterial spurting (Forrest IA). The bleeding continued despite an epinephrine solution (1:10 000) injection and bipolar cautery coagulation. Finally, hemostasis was achieved after the injection of $1.0 \mathrm{ml}$ (2 injections of $0.5 \mathrm{ml}$ ) of cyanoacrylate into the ulcer's base. During "second look" EGD, performed 5 days after the initial procedure, a healing ulcer with a clean base (Forrest III) on the posterior duodenal wall was revealed.

\section{Patient 4}

A 63-year-old man, with chronic renal failure, hemodialyzed 3 times a week and receiving heparin during dialysis, with a history of recurrent NUGIB, presented with melena. The EGD revealed an oozing vessel at the base of an ulcer on the posterior wall of the duodenal bulb. An epinephrine solution (1 : 10 000) injection and bipolar cautery coagulation failed to arrest the bleeding. Subsequently, $1.0 \mathrm{ml}$ (2 injections of $0.5 \mathrm{ml}$ ) of cyanoacrylate was injected into the ulcer's base and hemostasis was achieved. Unfortunately, the patient experienced recurrent bleeding symptoms 2 days later, after the next hemodialysis. The control EGD demonstrated an ulcer with a visible non-bleeding vessel (Forrest IIA) on the posterior wall of the duodenal bulb. An epinephrine solution was injected into the ulcer's base, after which the vessel was coagulated with a bipolar cautery.

\section{Patient 5}

A 30-year-old man, without previous medical history, presented with bloody and coffee ground emesis. An urgent EGD was performed and a bleeding gastric Dieulafoy's lesion (in the gastric fundus) was localized. Hemostasis with an epinephrine solution (1: 10 000) injection and bipolar cautery coagulation was unsuccessful. Subsequently, injection of $1.5 \mathrm{ml}$ (3 injections of $0.5 \mathrm{ml}$ ) of cyanoacrylate into the bleeding lesion, with the endoscope in the retroflexed position, provided bleeding arrest. The control
EGD, implemented 5 days later, demonstrated a small erosion in the place of the previously bleeding area.

\section{Discussion}

Endoscopic management of active upper gastrointestinal bleeding varies according to the type of bleeding but generally involves an epinephrine solution injection, bipolar cautery and the use of hemostatic clips [12]. Cyanoacrylate is widely used in the management of bleeding esophageal and gastric varices, whereas it is not recommended for acute non-variceal upper gastrointestinal bleeding. However, in difficult-to-arrest non-variceal bleeding it could be useful and a safe therapeutic tool.

In our studies hemostasis was achieved in all 5 cases while only one of them experienced re-bleeding 2 days after the initial procedure. In our opinion, this episode of recurrent bleeding was triggered by heparin anticoagulation administration, which had been performed because of chronic renal failure. Those aforementioned results are consistent with other studies. In a recently published case series study by Walia et al., initial hemostasis with a cyanoacrylate injection was achieved in all patients with difficult-to-arrest gastrointestinal bleeding and recurrent bleeding was observed in only one patient after cyanoacrylate spraying [13]. In another study by Prachayakul et al., 5 patients with bleeding upper gastrointestinal tumors were successfully treated with cyanoacrylate spraying and only one of them experienced re-bleeding [14]. Similarly, in a case series described by Shida et al., initial hemostasis was achieved in all cases, including bleeding tumors, duodenal ulcer and bleeding after endoscopic mucosal resection [15]. These studies, as well as our own results, proved the effectiveness of cyanoacrylate in the management of non-variceal upper gastrointestinal bleeding.

In previously published studies concerning application of cyanoacrylate in non-variceal gastrointestinal bleeding, the glue was injected directly into the area of bleeding $[16,17]$ or sprayed over the bleeding lesion [13-15]. Injection of cyanoacrylate into the blood vessel raises a concern about thromboembolic complications [10]. On the other hand, application of cyanoacrylate beside the blood vessel could induce inflammation and tissue necrosis [18]. The use of an alternative administration technique, cyanoacrylate spraying, causes its polymerization and formation of a hard, strong film over the bleeding area [19]. In our 
study cyanoacrylate was injected into blood vessels, as well as into the surrounding tissues. Moreover, in one case the glue was additionally sprayed over the bleeding point. No immediate or delayed adverse events/complications after cyanoacrylate application were observed. The control endoscopy revealed no changes or healing lesions in the region of the primary endoscopic interventions, and no complications attributed to cyanoacrylate during the follow-up period were observed. The amount of glue used was similar to that applied in other studies $[13,15]$.

Another important issue is the potential risk of endoscopic equipment damage after coming into contact with cyanoacrylate [20]. Moreover, rapid polymerization of cyanoacrylate can result in premature solidification of the glue in the needle [21]. This situation can be prevented by prior immersion of the end of the endoscope and needle tip into lipiodol or by temporarily disconnecting the suction mechanism [8]. In our studies we did not notice any damage to the endoscope or other equipment.

\section{Conclusions}

Cyanoacrylate injection and/or spraying are safe and effective methods to achieve immediate hemostasis when conventional endoscopic treatment is unsuccessful. Moreover, this technique is easy to perform and should be considered in cases of patients with difficult-to-arrest acute non-variceal upper gastrointestinal bleeding. However, further prospective studies are required to confirm the safety and effectiveness of our novel method.

\section{Acknowledgments}

The study was supported by Medical University of Bialystok (grant 143-18-563-L).

\section{References}

1. Lau JY, Barkun A, Fan DM, et al. Challenges in the management of acute peptic ulcer bleeding. Lancet 2013; 381: 2033-43.

2. Hearnshaw SA, Logan RF, Lowe D, et al. Acute upper gastrointestinal bleeding in the UK: patient characteristics, diagnoses and outcomes in the 2007 UK audit. Gut 2011; 60: 1327-35.

3. Wang YR, Richter JE, Dempsey DT. Trends and outcomes of hospitalizations for peptic ulcer disease in the United States, 1993 to 2006. Ann Surg 2010; 251: 51-8.

4. Kovacs TO, Jensen DM. Endoscopic treatment of ulcer bleeding. Curr Treat Options Gastroenterol 2007; 10: 143-8.

5. Jairath V, Kahan BC, Logan RF, et al. National audit of the use of surgery and radiological embolization after failed endoscopic haemostasis for non-variceal upper gastrointestinal bleeding. Br J Surg 2012; 99: 1672-80.

6. Loffroy R, Guiu B. Role of transcatheter arterial embolization for massive bleeding from gastroduodenal ulcers. World J Gastroenterol 2009; 15: 5889-97.

7. Lau JY, Sung JJ, Lam YH, et al. Endoscopic retreatment compared with surgery in patients with recurrent bleeding after initial endoscopic control of bleeding ulcers. N Engl J Med 1999; 340: 751-6.

8. Cameron R, Binmoeller KF. Cyanoacrylate applications in the GI tract. Gastrointest Endosc 2013; 77: 846-57.

9. Soehendra N, Nam VC, Grimm H, Kempeneers I. Endoscopic obliteration of large esophagogastric varices with bucrylate. Endoscopy 1986; 18: 25-6.

10. Cheng LF, Wang ZQ, Li CZ, et al. Treatment of gastric varices by endoscopic sclerotherapy using butyl cyanoacrylate: 10 years' experience of 635 cases. Chin Med J (Engl) 2007; 120: 2081-5.

11. Mattamal GJ. US FDA perspective on the regulations of medical-grade polymers: cyanoacrylate polymer medical device tissue adhesives. Expert Rev Med Devices 2008; 5: 41-9.

12. Kwan V, Norton I. Endoscopic management of non-variceal upper gastrointestinal haemorrhage. ANZ J Surg 2007; 77: 222-30.

13. Walia SS, Sachdeva A, Kim JJ, et al. Cyanoacrylate spray for treatment of difficult-to-control Gl bleeding. Gastrointest Endosc 2013; 78: 536-9.

14. Prachayakul V, Aswakul P, Kachinthorn U. Spraying N-butyl2-cyanoacrylate (Histoacryl) as a rescue therapy for gastrointestinal malignant tumor bleeding after failed conventional therapy. Endoscopy 2011; 43 Suppl. 2: E227-8.

15. Shida T, Takano S, Miyazaki M. Spraying n-butyl-2-cyanoacrylate (Histoacryl) might be a simple and final technique for bleeding gastrointestinal lesions. Endoscopy 2009; 41 Suppl. 2: E27-8.

16. Lee KJ, Kim JH, Hahm KB, et al. Randomized trial of N-butyl-2-cyanoacrylate compared with injection of hypertonic saline-epinephrine in the endoscopic treatment of bleeding peptic ulcers. Endoscopy 2000; 32: 505-11.

17. Kurokohchi K, Maeta T, Ohgi T, et al. Successful treatment of a giant blood vessel in a gastric ulcer by endoscopic sclerotherapy with N-butyl-2-cyanoacrylate. Endoscopy 2007; 38: E250.

18. Farooq FT, Wong RCK. Injection sclerotherapy for the management of esophageal and gastric varices. Tech Gastrointest Endosc 2005; 7: 8-17.

19. Singer AJ, Quinn JV, Hollander JE. The cyanoacrylate topical skin adhesives. Am J Emerg Med 2008; 26: 490-6.

20. Huang YH, Yeh HZ, Chen GH, et al. Endoscopic treatment of bleeding gastric varices by $\mathrm{N}$ butyl-2-cyanoacrylate (Histoacryl) injection: longterm efficacy and safety. Gastrointest Endosc 2000; 52: 160-7.

21. Petersen B, Barkun A, Carpenter S, et al. Tissue adhesives and fibrin glues. Gastrointest Endosc 2004; 60: 327-33.

Received: 9.04.2014, accepted: 20.05.2014. 